\title{
Some New Evidence for Polymorphism in Cold-Crystallized and Melt-Crystallized Poly(ether ether ketone)
}

\author{
C.-Y. CHEN and E. M. Woo ${ }^{\dagger}$ \\ Department of Chemical Engineering, National Cheng Kung University, \\ Tainan, Taiwan 701-01, R.O.C.
}

(Received September 9, 1994)

\begin{abstract}
Cold-crystallized or melt-crystallized poly(ether ether ketone) (PEEK) has been found to display multiple low-temperature minor peaks in addition to the major melting peak. Experimental evidences of thermal analysis and X-ray diffraction studies are provided in this study to support the proposal of multiple morphologies being responsible for the observed multiple melting behavior. The hypothesis of melting of original low-temperature crystals and reorganization into higher-melt crystals during DSC scanning has been found to lack plausible evidences. When step-wise crystallized or annealed in decending temperatures, the minor crystals could aggregate into several populations with each showing a distribution. The results of slow-cooled PEEK suggested that the minor crystals have a tendency to populate in the region where the minor melting peak position is located at 310 and $320^{\circ} \mathrm{C}$. We have exemplified the co-existence of thinner lamellae of multiple thickness distributions simultaneously with the major lamellae after crystallization or annealing treatments. The polymorphism in PEEK exists on the lamellar scales.

KEY WORDS Differential Scanning Calorimetry / Polymorphism / Dual Morphology / Poly(ether ether ketone) (PEEK) / Multiple Melting / Lamellar Thickening / Crystallization /
\end{abstract}

Double-melting, or more correctly speaking, multiple melting endotherms in semicrystalline polymers have been observed in some semicrystalline polymers during thermal analysis for many years. Historically, the most notable has been poly(ethylene terephthalate) (PET). ${ }^{1-6}$ Poly(butylene terephthalate) $(\mathrm{PBT})^{7-11}$ has been reported to exhibit similar behavior. More recently, high-temperature semicrystalline thermoplastic such as poly(phenylene sulfide) (PPS) ${ }^{12,13}$ and poly(ether ether ketone) (PEEK) $)^{14-19}$ have also been found to exhibit multiple melting behavior when crystallized at a series of isothermal temperatures.

Although the origin of the phenomenon has been the subject of many intense research activities, the issue and its explanations still remain controversial enough. Dramatically different mechanisms have been proposed by investigators to explain their findings. In early days, double melting (in the main melting region of the polymer) was once attributed to melting of two crystals of different morphologies, such as the fully extended vs. foldedchain structures, which were responsible for the double melting. This was later considered not likely. Roberts presented small angle $\mathrm{X}$ ray diffraction data and claimed that two folded lamellar structures $(120 \mathrm{~A}$ and $150 \mathrm{~A}$, respectively) were present in an annealed PET. ${ }^{6}$ The dual morphology model states that a dual morphology is present in semicrystalline polymers that exhibit dual endotherms.9,14 Ludwig and Eyerer ${ }^{11}$ reported dual morphology, the usual and unusual spherulites, in PBT and stated that the melting at $225^{\circ} \mathrm{C}$ is correlated with the unusual type (larger spheru-

\footnotetext{
† To whom correspondence should be addressed.
} 
lites) and the melting at $220^{\circ} \mathrm{C}$ is correlated with the usual type (smaller spherulites). The dual-morphology model, however, is commonly associated with polymers showing doublet melting peak in the main melting region, but has yet to explain the multiple minor endotherms below the main melting.

Other investigations proposed that crystallization at lower temperatures may produce crystals that may have a low degree of perfection and can melt and recrystallize to yield crystals of better perfection or greater thickness upon heating to a higher temperature during DSC thermal scanning. It has been proposed by several investigators ${ }^{20,21}$ in claiming that "the dual melting peaks" can arise in the absence of bimodal crystal types. That is, the dual melting behavior is merely a "doublet appearance" of thermal behavior of a single crystal morphology that is undergoing melting, recrystallization, and remelting. This proposal hypothesizes that the multiple peaks are related to melting and recrystallization, and remelting of one original crystalline morphology.

Blundell ${ }^{14}$ proposed that if the first hypothesis (co-existence of polymorphism) is correct, then there should be no substantial changes as a result of recrystallization when a sample is heated in DSC in the region between the two melting regions. On the other hand, if the second hypothesis (recrystallization/remelting) is correct, one would expect a continuous change. This study hypothesized that the multiple peaks were associated with two or more distinct crystalline morphologies. ${ }^{19}$ It was intended to provide experimental evicence to support the polymorphism hypothesis by conducting differential scanning calorimetry and X-ray scattering experiments on PEEK samples which had been subjected to various prescribed thermal treatments.

\section{EXPERIMENTAL}

\section{Materials and Preparation}

Poly(ether ether ketone) (PEEK) $\left(M_{n}=14,000\right.$ $\left.\mathrm{g} \mathrm{mol}^{-1}, \mathrm{ICI}\right)$ were obtained in a high-purity, additive-free film form. The main starting polymer specimens were PEEK isothermally cold- or melt-crystallized at a chosen isothermal temperatures or crystallized step-wise at a series of isothermal temperatures. The starting specimens were then subjected to prescribed thermal treatments. Crystallization and thermal treatments were performed in the chamber of the differential scanning calorimeter. Since all thermal treatments were conducted in the DSC, the temperature accuracy and control for annealing or crystallization of the polymer samples was excellent. Only for the samples that required extended times of treatment, they were first treated in DSC at the designated temperature until further change in the samples was judged to be minimal or negligible. Then the samples were quickly removed from the DSC chamber to an oven that had been pre-set at the same temperature to continue the briefly interrupted thermal treatments.

The sole intent of prescription of various thermal treatments was to confirm whether the multiple melting behavior was related to polymorphism or recrystallization/remelting mechanism.

\section{Differential Scanning Calorimetry}

A power-compensated type of differential scanning calorimeter (Perkin-Elmer DSC 7, equipped with an intracooler and a DEC computer for data acquisition/analysis) was used for various thermal treatments (quenching, annealing, or cold- or melt-crystallization) of the samples and to observe the melting endothermic peaks. The temperature and heat of melting were calibrated with a high-purity indium standard. The newly improved capability of the DSC to heat and cool the polymer samples at extremely fast rates have helped to enhance the accuracy of the data by reaching 
and equilibrating at the targeted isothermal temperatures. Relatively small sample sizes (2- $4 \mathrm{mg}$ ) were used to minimize the effect of low thermal conductivities of the polymers. After specific thermal treatments, the polymer samples were scanned from ambient temperature to approximately $25^{\circ} \mathrm{C}$ above the respective melting temperature of each polymer at a scanning rate of $10^{\circ} \mathrm{Cmin}^{-1}$, unless otherwise indicated. During the thermal treatments and DSC scanning, a nitrogen purge was provided throughout. In thermal treatments of the samples, the fastest heating rate $\left(+500^{\circ} \mathrm{C}\right.$ $\left.\min ^{-1}\right)$ or cooling rate $\left(-320^{\circ} \mathrm{Cmin}^{-1}\right)$ was used to prevent non-isothermal crystallization.

\section{Wide-Angle X-Ray (WAXS) Diffraction}

The X-ray instrument used was Rigaku D/Max II B with copper $K_{\alpha}$ radiation and a wavelength of 1.542 angstroms. PEEK specimens of various thermal treatments after cold- or melt-crystallization were prepared in similar methods as described for the thermal analysis samples. X-Ray diffraction was performed on the specimens of cold- or melt crystallized polymer samples to examine possible difference in the crystal perfection in the lamellar structure. PEEK exhibits an orthorhombic crystal structure with the cell dimensions $a=7.75 \mathrm{~A}, b=5.92 \mathrm{~A}$, and $c=$ $10.00 \mathrm{~A}^{22}$ Possible alteration of the crystals in the PEEK samples of various thermal treatments and crystallization methods was examined using the X-ray diffraction technique.

\section{RESULTS}

Curve (a) in Figure 1 shows the DSC scan at $10^{\circ} \mathrm{C} \mathrm{min}^{-1}$ of PEEK sample that had been quenched from the melt state and subjected to isothermal crystallization at four temperatures: $310,290,250$, and $210^{\circ} \mathrm{C}$ consecutively for 30 minutes at each temperature. Four minor endothermic peaks were observed at 320.0, $300.2,261.5$, and $224.3^{\circ} \mathrm{C}$, in addition to the

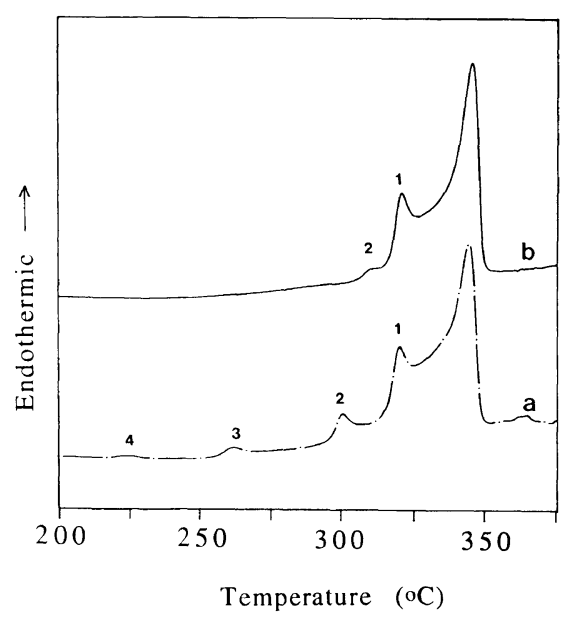

Figure 1. DSC scan of PEEK samples (a) meltcrystallized at $310,290,250$, and $210^{\circ} \mathrm{C}$ consecutively, (b) melt-crystallized at $310,290,250$, and $210^{\circ} \mathrm{C}$ and then pre-heated to $300^{\circ} \mathrm{C}$ to remove three of the four minor peaks.

main melting peak at $345.6^{\circ} \mathrm{C}$. Interestingly, the minor peaks at the higher isothermal crystallization temperatures tended to be stronger. For example, the third and fourth minor peak at the lowest two isothermal temperatures in the thermogram (b) of Figure 1 are only a barely visible and quite broad peaks. The height of the fourth minor peak is almost 0 , and therefore its half-width is about the same as the width at its base. Since the widths of all these four minor peaks are all about the same (the measurements of widths might vary slightly depending on how one draws the baseline), consequently, the halfwidths of the taller, stronger, peaks are definitely smaller. Thus, the comparison in the peak breadth indicates that the minor crystal entities responsible for that particular minor peak exhibit a narrower distribution (sharper peak) at a higher crystallization temperature. Of the four minor peaks, the minor peak at $320^{\circ} \mathrm{C}$ seems to be the most prominent and fastest growing in the same time. This might suggest that the minor crystal entities responsible for the minor peak at or near $320^{\circ} \mathrm{C}$ are more favored to grow than other minor 
crystals. Later, we will discuss this point further using the results of slow-cooled PEEK samples in the following sections. The same PEEK sample was then subjected to the above crystallization scheme and pre-heated to $305^{\circ} \mathrm{C}$ and then cooled down to $100^{\circ} \mathrm{C}$. The purpose of pre-heating to $305^{\circ} \mathrm{C}$ was to melt and remove all the minor peaks $\left(300.2,261.5\right.$, and $\left.224.3^{\circ} \mathrm{C}\right)$ except for the most prominent minor peak at $320.0^{\circ} \mathrm{C}$ and the main melting peak at $345.6^{\circ} \mathrm{C}$. Curve (b) of Figure 1 shows the DSC scan at $10^{\circ} \mathrm{C} \mathrm{min}^{-1}$ of the PEEK sample so prepared. As expected, the minor peak at 320.0 and the main melting peak at $345.6^{\circ} \mathrm{C}$ remained in the DSC thermogram. The temperature positions of these two peaks remain unchanged. Furthermore, the melting enthalpy of these two peaks (as measured by area integration) remained virtually the same regardless of the melting of the other lower-temperature minor peaks at $300.2,261.5$, and $224.3^{\circ} \mathrm{C}$. That is, the results have demonstrated no changes at all in the remaining higher-temperature peaks as a result of "recrystallization" of the melted minor crystal entities when the PEEK sample is heated in DSC in the region between the two melting regions.

The DSC results seem to suggest that the first hypothesis (coexistence of polymorphism) is correct. An important question to address here is that if indeed the hypothesized "recrystallization" phenomenon of the minor crystals does occur, is it responsible for the entire melting endotherm observed in the main melting region or just a small portion of it? Does it proceed fast enough that the recrystallized higher-melt crystal entities could be detected in time when the sample is scanned to the main melting region at the normal heating rate, say $10^{\circ} \mathrm{Cmin}^{-1}$ scanning rate? We will provide more detailed interpretation in the following sections.

Apparently, step-wise isothermal crystallization at multiple temperatures resulted in the observed minor melting endotherms spaced between the $T_{\mathrm{g}}$ and $T_{\mathrm{m}}$ of PEEK. It seems that

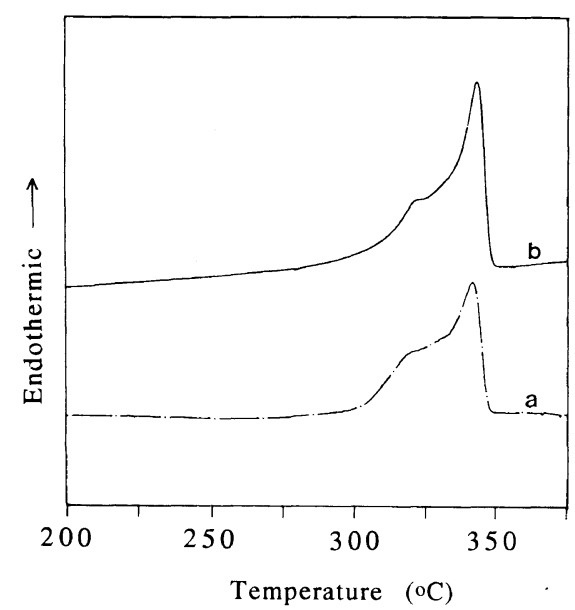

Figure 2. DSC thermograms of two PEEK samples (a) slow-cooled at $0.5^{\circ} \mathrm{Cmin}^{-1}$ from 300 to $50^{\circ} \mathrm{C}$, (b) slow-cooled at $0.5^{\circ} \mathrm{C} \mathrm{min}^{-1}$ from 375 to $175^{\circ} \mathrm{C}$.

lamellae of quite wide morphology distribution could exist in a semicrystalline polymer such as PEEK. Step-wise isothermal crystallization or annealing between $T_{m}$ and $T_{\mathrm{g}}$ tends to break up the original wide distribution to several narrower distributions, which appeared as minor endotherm peaks of different sharpness and intensity upon DSC scanning. It could be argued that the dynamic slow cooling from the melt state of PEEK would have an equivalent effect of infinitely small step-wise crystallization at an infinite number of isothermal temperatures. Thus, DSC scans on a PEEK sample having been subjected to extremely low cooling from the melt to glass transition temperature would reveal the natural morphology distribution of the minor crystals in the polymer. Figure 2 shows the DSC scans of two PEEK samples slow-cooled in two different ways. Curve (a) of Figure 2 shows the DSC thermogram at $10^{\circ} \mathrm{Cmin}^{-1}$ of the PEEK sample quenched from the melt to $300^{\circ} \mathrm{C}$ and then slow-cooled at $0.5^{\circ} \mathrm{C} \mathrm{min}^{-1}$ from 300 to $50^{\circ} \mathrm{C}$. Curve (b) of Figure 2 shows the DSC thermogram at $10^{\circ} \mathrm{Cmin}^{-1}$ of the PEEK sample slow-cooled at $0.5^{\circ} \mathrm{C} \mathrm{min}^{-1}$ from 375 to $175^{\circ} \mathrm{C}$. The two thermograms are quite similar, other than a slight difference in the 


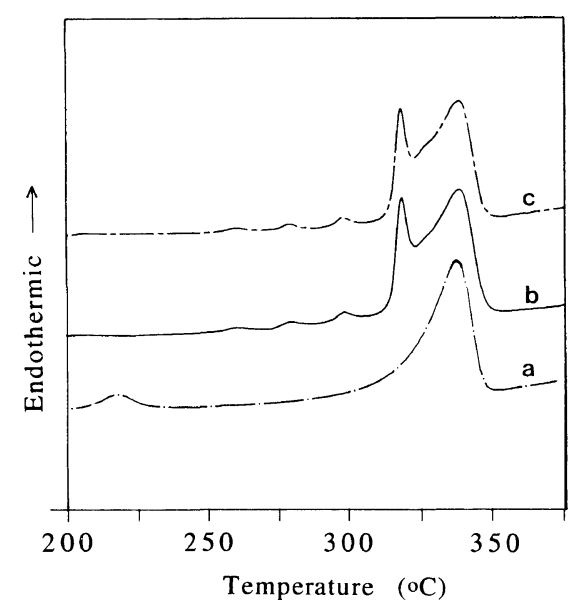

Figure 3. DSC thermograms of the PEEK (a) coldcrystallized at $190^{\circ} \mathrm{C}$. for $38.5 \mathrm{~h}$, (b) cold-crystallized at 310 , $290,270,250$, and $190^{\circ} \mathrm{C}$, (c) cold-crystallized at $190^{\circ} \mathrm{C}$ for $38.5 \mathrm{~h}$, and then annealed at $310,290,270,250$, and $190^{\circ} \mathrm{C}$.

peak sharpness. Both DSC curves exhibit a rather sharp main melting peak at 342 $343^{\circ} \mathrm{C}$. The most striking feature is that, in addition to the main melting peak, a quite broad shoulder peak exists at about 310 $320^{\circ} \mathrm{C}$. The melting results of the slow-cooled PEEK samples suggested that morphology dimensions of the minor crystal entities had a stronger tendency to aggregate in the region that would exhibit a minor melting endotherm at around $310-320^{\circ} \mathrm{C}$ upon DSC scanning at $10^{\circ} \mathrm{C} \mathrm{min}^{-1}$. Aggregation in other regions was possible too, when the sample was held at selected temperatures for long enough time.

For direct comparisons with the meltcrystallized samples, we also investigated the melting behavior of the cold-crystallized PEEK. Figure 3 shows the DSC scans at $10^{\circ} \mathrm{Cmin}^{-1}$ of theree PEEK samples coldcrystallized in three different ways. Curve (a) of Figure 3 shows the thermogram of the PEEK cold-crystallized at $190^{\circ} \mathrm{C}$ for $38.5 \mathrm{~h}$ (2,310 minutes). For the long time of $38.5 \mathrm{~h}$ at $190^{\circ} \mathrm{C}$, the sample could be regarded as having crystallized to its maximum crystallinity that could be attained at the temperature of $190^{\circ} \mathrm{C}$.
The main melting endotherm appears as a single peak with the peak temperature at $337.6^{\circ} \mathrm{C}$ and a peak area of $41.0 \mathrm{~J} \mathrm{~g}^{-1}$. A broad low-temperature minor endotherm is observed with a peak temperature of $217^{\circ} \mathrm{C}$ and a peak area of $3.6 \mathrm{~J} \mathrm{~g}^{-1}$. The occurrence of this minor peak is apparently due to the isothermal annealing at $190^{\circ} \mathrm{C}$ for $38.5 \mathrm{~h}$. It has been reported that the difference between this peak position and the annealing temperature can increase logarithmically with time. ${ }^{19}$ Curve (b) of Figure 3 shows the thermogram of the PEEK cold-crystallized consecutively at five isothermal temperatures: $310,290,270,250$, and $190^{\circ} \mathrm{C}$ for $0.5 \mathrm{~h}$ at each step of temperature. As a result of annealing at these five temperatures, five minor melting endotherms, with the peaks at $318.6,298.0,278.7,259.5$, and $204.4^{\circ} \mathrm{C}$, and the main melting peak at $339^{\circ} \mathrm{C}$ are observed in the DSC thermogram of this PEEK sample. Of the five minor peaks, the highesttemperature minor peak $\left(318.2^{\circ} \mathrm{C}\right)$ is sharp and intense, while the lowest-temperature minor peak $\left(204.4^{\circ} \mathrm{C}\right)$ is so weak that it is only barely observable. As a matter of fact the highesttemperature minor peak $\left(318.2^{\circ} \mathrm{C}\right)$ is so strong and intense that this minor peak together with the main melting peak appears as "doublet melting peaks". The hypothesis of recrystalization/remelting has attempted to explain the multiple peaks or the doublet melting peaks as a result of recrystallization and remelting of an original lower-melt crystal. Obviously, multiple morphologies, possibly on the lamellar scales, are responsible for the multiple melting phenomenon. There would be difficulty if one utilizes the recrystallization/remelting mechanism of explain the multiple endotherms behavior observed in this sample. Cruve (c) of Figure 3 shows the thermogram of the PEEK cold-crystallized first at $190^{\circ} \mathrm{C}$ for $38.5 \mathrm{~h}$ and then consecutively at five isothermal temperatures: $310,290,270,250$, and $190^{\circ} \mathrm{C}$ for $0.5 \mathrm{~h}$ at each step of temperature. Again, five minor melting endotherms, with the peaks at 318.6, $298.1,278.8,259.5$, and 204.0, and the main 
melting peak at $339.5^{\circ} \mathrm{C}$ are observed in the DSC thermogram of this PEEK sample. The temperatures of these peaks are virtually the same as those observed in Curve (b). Most notably, the breadth of the upper part of the main melting peak remain the same regardless of the presence of the minor endotherm peak, suggesting the independence of the minor endotherm from the main peak. The sharp minor peak at $318^{\circ} \mathrm{C}$ observed in these two PEEK samples should suggest that the minor crystal entities for this sub- $T_{\mathrm{m}}$ peak might be indeed in coexistence with simultaneous existing crystal entities of the main melting peak. In other words, the melting of the minor crystal at $318^{\circ} \mathrm{C}$ is independent and has nothing to do with the appearance of the major melting peak at $339^{\circ} \mathrm{C}$. Furthermore, if one compares directly Curve (a), Curve (b) and Curve (c) in this same figure, it can be easily seen the Curve (c) is actually an additive superposition of the sharp minor peak at $318.2^{\circ} \mathrm{C}$ observed in Curve (b) with Curve (a). This again suggests that the crystal responsible for the minor peak at $318^{\circ} \mathrm{C}$ and other low-temperature minor peaks further below are independent from the crystal responsible for the major melting peak at $339^{\circ} \mathrm{C}$. That is, polymorphism in PEEK, in the form of multiple lamellar distributions, is responsible for the multiple melting phenomenon.

Figure 4 shows the DSC scans at $10^{\circ} \mathrm{C} \mathrm{min}^{-1}$ of the PEEK sample cold-crystallized consecutively at $210,250,290,310,290$, and $250^{\circ} \mathrm{C}$ for 30 minutes at each step. Note that the annealing at the highest temperature of $310^{\circ} \mathrm{C}$ would have melted the three minor peaks caused by consecutive crystallization at 210 , 250 , and $290^{\circ} \mathrm{C}$. However, when the sample was annealed again back at 290 and $250^{\circ} \mathrm{C}$ for 30 minutes after the $310^{\circ} \mathrm{C}$ step, the DSC curve of the sample still exhibited two minor peaks at 300.4 and $261.7^{\circ} \mathrm{C}$, in addition to the preserved minor peak at $320.8^{\circ} \mathrm{C}$ (which as discussed earlier is due to crystallization at $310^{\circ} \mathrm{C}$ ). The magnitudes and peak positions of

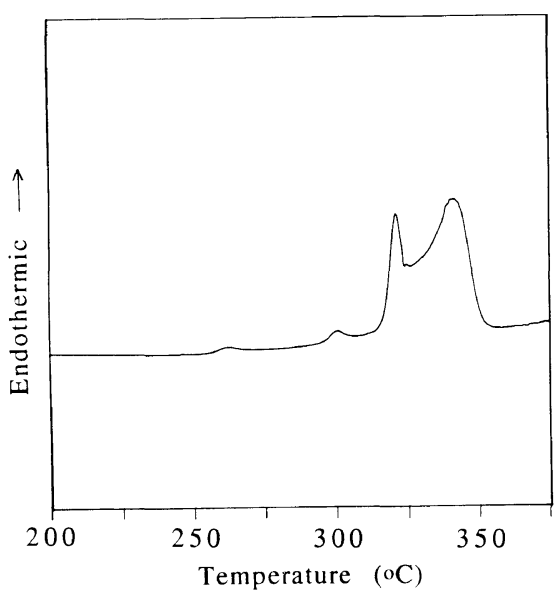

Figure 4. DSC scans at $10^{\circ} \mathrm{C} \mathrm{min}^{-1}$ of the PEEK sample cold-crystallized consecutively at 210, 250, 290, 310, 290, and $250^{\circ} \mathrm{C}$ for 30 minutes at each step.

these two re-generated peaks are exactly the same as the original peaks due to the cold crystallization at 290 and $250^{\circ} \mathrm{C}$ (see the results discussed in Fig. 3). The purpose of this experiment was to demonstrate the reversibility of the low-temperature minor peaks. If the recrystallization/remelting mechanism were at work, the minor crystal entities would have disappeared by melting and reorganized into higher-melt crystal species that could remelt later at a higher temperature. Thus when back annealed at 290 and $250^{\circ} \mathrm{C}$ after the consecutive $210,250,290$, and $310^{\circ} \mathrm{C}$ treatment, the polymer would not have exhibited again minor peaks at 300.4 and $261.7^{\circ} \mathrm{C}$. Our experimental results clearly contradicted this argument based on recrystallization/remelting.

To investigate how the rates of heating between the minor peak and the main melting peak might affect the relative magnitudes of the minor and main melting endotherms, we devised the following experimental schemes. Three amorphous PEEK samples were scanned at 1,5 , and $10^{\circ} \mathrm{C} \mathrm{min}^{-1}$ from ambient to $310^{\circ} \mathrm{C}$ before being immediately quenched back to ambient temperature. Apparently the dynamic heating between ambient and $310^{\circ} \mathrm{C}$ induced crystallization in PEEK. The three dynamically 


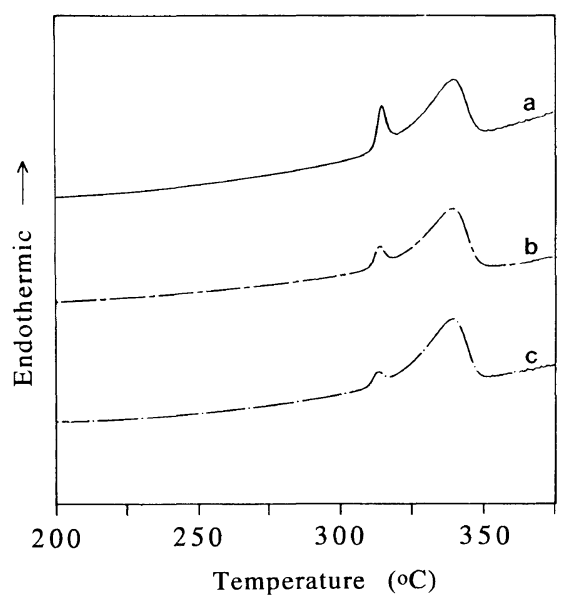

Figure 5. DSC scans at $10^{\circ} \mathrm{Cmin}^{-1}$ of three PEEK samples previously subjected to non-isothermal crystallization by heating at (a) $1^{\circ} \mathrm{Cmin}^{-1}$, (b) $5^{\circ} \mathrm{Cmin}^{-1}$, and (c) $10^{\circ} \mathrm{C} \mathrm{min}^{-1}$.

heated PEEK samples were then scanned all at $10^{\circ} \mathrm{C} \mathrm{min}{ }^{-1}$ from the ambient to $375^{\circ} \mathrm{C}$. Figure 5 shows the DSC scans at $10^{\circ} \mathrm{C} \mathrm{min}^{-1}$ of these three PEEK samples, where Curves (a), (b), and (c) are the PEEK samples previously subjected to non-isothermal crystallization by heating at 1,5 , and $10^{\circ} \mathrm{Cmin}^{-1}$, respectively from ambient to $310^{\circ} \mathrm{C}$. All three scans revealed a main melting peak at the same temperature of $339.4^{\circ} \mathrm{C}$. Surprisingly, a minor peak at the same temperature $314^{\circ} \mathrm{C}$ was also observed in the all the three thermograms, but the peak intensity distinctly differed among the three samples. The PEEK sample subjected to pre-heating to $310^{\circ} \mathrm{C}$ at $10^{\circ} \mathrm{C} \mathrm{min}^{-1}$ exhibits only a negligibly small endotherm (Curve c). By comparison, the PEEK sample subjected to pre-heating at 1 and $5^{\circ} \mathrm{Cmin}^{-1}$ exhibit a relatively larger minor endotherms at $314^{\circ} \mathrm{C}$, indicating that a longer time during the dynamic heating resulted in greater magnitude of the minor endotherm. The different heating did not seem to have any effect at all on the main melting peak. Recall that a dynamic heating of an amorphous PEEK from ambient to $375^{\circ} \mathrm{C}$ would reveal a main melting peak at $339^{\circ} \mathrm{C}$ but not the minor melting endotherm.

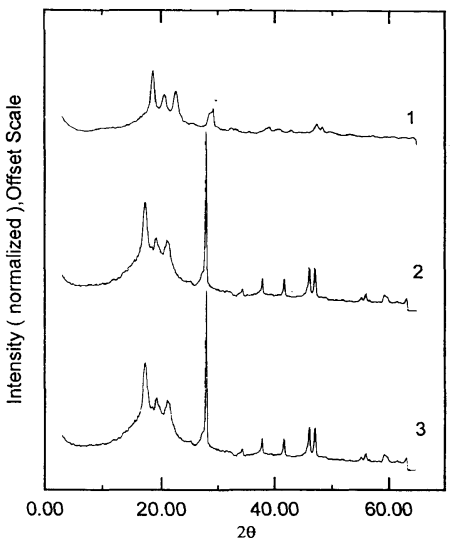

Figure 6. X-ray crystallographs of PEEK (a) meltcrystallized at $270^{\circ} \mathrm{C}$ for $30 \mathrm{~min}$, (b) cold-crystallized at $270^{\circ} \mathrm{C}$ for $30 \mathrm{~min}$, and (c) cold-crystallized at $190^{\circ} \mathrm{C}$ for $38.5 \mathrm{~h}$.

Apparently this minor peak at $314^{\circ} \mathrm{C}$ was a result of dynamic heating from ambient to $310^{\circ} \mathrm{C}$. Had the heating been continued from 310 to $375^{\circ} \mathrm{C}$ in the pre-scan, the minor melting peak would have been merged into the main melting peak. Since the main melting endotherm did not seem to be affected by the different thermal treatments earlier imposed on the PEEK, it could be construed that the melting of the minor crysral and reorganization during heating scan was limited only to this small portion of crystals responsible for the minor melting endotherms. That is, the main melting endotherm is the melting of originally formed crystals and not a result of melting, recrystallization of original thin lamellae. Again, the above analysis should demonstrate that the crystal entities responsible for the multiple minor melting endotherms are independently formed during non-isothermal or isothermal annealing or crystallization as distinct species. They are labeled as "minor crystals", which are distinguishable from the main crystals responsible for the main melting peak.

Figure 6 shows the comparison of the X-ray crystallographs of the cold-crystallized and melt-crystallized PEEK samples. Crystallo- 
graphs (1)-(3) are the $270^{\circ} \mathrm{C}$ melt-crystallized PEEK for 30 minutes, $270^{\circ} \mathrm{C}$ cold-crystallized for 30 minutes, and $190^{\circ} \mathrm{C}$ cold-crystallized for $38.5 \mathrm{~h}$, respectively. The literature ${ }^{22}$ has reported the diffraction peaks for PEEK at $2 \theta=18.7,20.7,22.6$, and $28.7^{\circ}$, for (110), (113), (200), and (213) planes, respectively. The results show that peaks positions are all the same, indicating that the unit cell did not change as a result of different crystallization methods. Due to background scattering from the aluminum substrate, the peak at $2 \theta=28.7^{\circ}$ for the two cold-crystallized PEEK appeared much sharper and greater in intensity. In reality, all the reflection peak positions and intensities were all identical. The results from $\mathrm{X}$-ray scattering suggested that although the unit cells remained the same, but the lamellae were thickened to different levels upon treatment at multiple isothermal temperatures. Thus, the polymorphism in PEEK is not on the unit cell level, but most likely on the scale of lamellae.

\section{DISCUSSIONS}

Although some investigators ${ }^{23}$ suggested that multiple melting peaks in PEEK may simply arise from melting and recrystallization taking place during scanning in the calorimeter and that the multiple melting does not necessarily reflect the morphology present in the sample before scanning, we believe that the polymer morphology contains lamellae of various thickness dependent on the temperatures of crystallization. When a semicrystalline polymer is crystallized, majority of the polymer chains forms crystal lamellae with the thickness equal or near the equilibrium value. These crystals would melt at the main melting point. In addition, some smaller portion of the polymer, however, may develop crystals of minor lamellar thickness that are dependent on the crystallization temperatures. The melting point distribution of these minor lamellar crystals are also dependent on the range of

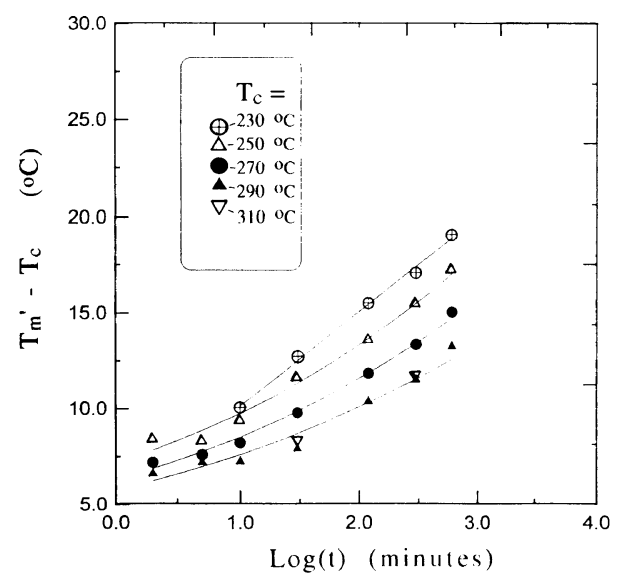

Figure 7. Increase of melting temperatures of the minor crystals as a function of $\log$ (time).

the crystallization or annealing temperatures. In contrast with a slow-cooled polymer, crystallization or annealing on a selected temperature has the effect of redistributing the minor crystals to aggregate into a more concentrated population. If the crystallization is performed step-wise on a decending multiple temperatures, aggregation of the minor crystals forms several groups of minor crystals with different lamellar thickness distributions. The Hoffman's equation ${ }^{24}$ gives: $T_{\mathrm{m}}^{\prime}=T_{\mathrm{m}}^{\circ} \quad(1-$ $\left.2 \sigma_{\mathrm{e}} / \Delta H_{f} \cdot L\right)$, where $T_{\mathrm{m}}^{\circ}$ is the melting point of an infinite perfect crystal, $\sigma_{\mathrm{e}}$ is the surface energy of the crystals, $\Delta H_{\mathrm{f}}$ the heat of fusion, and $L$ the lamellar crystal thickness. The equation indicates lower melting points for lamellae of smaller $L$. The results in this study suggest that the lamellae could develop to different thickness at different temperatures, and those of smaller thickness would melt at lower temperatures. Bassett and Patel ${ }^{25}$ have done a transmission electron microscopy study on isotactic poly(4-methylpenetene-1) and found that the measured average lamellar thickness of the polymer increases logarithmically with the time of annealing at a temperature of $241^{\circ} \mathrm{C}$. The finding by Bassett and Patel seems to agree well with our DSC observation, as shown in Figure 7, that the melt- 
ing peak temperatures of the minor crystals entities in the melt-crystallized PEEK samples increase logarithmically with time.

In a previous report ${ }^{19}$ on closely related subjects, we have proposed that within a spherulite, the minor crystal entities are probably thin lamellar branches located in the outer peripheral of spherulites or exist as imperfect inter-spherulite crystal-like micelles highly impinged by the growing front of sperulites. These thin lamellae can exist with multiple populations of thickness, depending on the cooling or isothermal hold treatment after a melting process. Furthermore, our recent study ${ }^{26}$ on the crystallization behavior of PPS has also provided evidences for sequential growth of the minor crystals (thin lamellae) following the regular lamellae.

\section{CONCLUSION}

The multiple melting phenomenon of PEEK is attributed to the fact that thin lamellae of variable thickness in addition to the main lamellae of a relatively constant thickness distribution could develop as a result of crystallization or cold annealing. We have exemplified the co-existence of thinner lamellae of multiple thickness distributions simultaneously with the major lamellae after crystallization or annealing treatments. The hypothesis of melting of original low-temperature crystals and reorganization into higher-melt crystals during DSC scanning has been found to lack plausible evidences. It has also been found that of the series of minor crystals formed below the main melting temperature, the minor crystals have a stronger tendency to populate in the region where the peak position is located at 310 and $320^{\circ} \mathrm{C}$, which is due to crystallization or annealing treatments of PEEK at $300^{\circ} \mathrm{C}$. The minor peaks in this temperature region are particularly sharp and fastest growing. This could also be observed in the DSC scans of slow-cooled PEEK, revealing the existence of a shoulder peak in this region, although the shoulder peak was not as distinctly sharp as the one generated by isothermal crystallization or annealing at $300^{\circ} \mathrm{C}$. These minor peaks could be removed or regenerated independently under prescribed thermal treatments without affecting the main melting endotherm. In summary, polymorphism in PEEK is responsible for the observed multiple minor peaks and the polymorphism is suggested to exist on the lamellar scale, and not on the unit cell scale.

Acknowledgments. The author (EMW) acknowledges the competitive university grant in acquiring the DSC instrument used in this study. The financial support (NSC 83-0405E006-029) is provided by National Science Council of the Republic of China (Taiwan). The technical assistance provided by Mr. T. Y. $\mathrm{Ko}$ is also appreciated.

\section{REFERENCES}

1. P. Holdsworth and A. Turner-Jones, Polymer, 12, 195 (1971).

2. G. C. Alfonso, E. Pedemonte, and L. Ponzetti, Polymer, 20, 104 (1979).

3. G. E. Sweet and J. P. Bell, J. Polym. Sci., A-2, 10, 1273 (1972).

4. S. B. Lin and J. L. Koenig, J. Polym. Sci., Polym. Phys. Ed., 21, 2365 (1983).

5. F. Fountain, J. Ledent, G. Groeninckx, and $\mathbf{H}$. Reynaers, Polymer, 23, 185 (1982).

6. R. C. Roberts, Polymer, 10, 117 (1969).

7. S. Y. Hobbs and C. F. Pratt, Polymer, 16, 462 (1975).

8. R. S. Stein and A. Misra, J. Polym. Sci., Phys. Ed., 18, 327 (1980).

9. J. T. Yeh and J. Runt, J. Polym. Sci., Polym. Phys. Ed., 27, 1543 (1989).

10. H. J. Ludwig and P. Eyerer, Polym. Eng. Sci., 28, 143 (1988).

11. J. C. Stevenson and S. L. Cooper, J. Polym. Sci., Phys. Ed., 26, 953 (1988).

12. K. Mai, M. Zhang, H. Zeng, and S. Qi, J. Appl. Polym. Sci., 51, 57 (1994).

13. P. Cebe and S. Chung, Polym. Composites, 11, 265 (1990).

14. D. J. Blundell, Polymer, 28, 2248 (1987).

15. Y. Lee, R. S. Porter, and J. S. Lin, Macromolecules, 22, 1756 (1989).

16. Y. Lee and R. S. Porter, Macromolecules, 20, 1336 (1987). 
17. S. S. Chang, Polym. Commun., 29, 138 (1988).

18. P. Huo and P. Cebe, Colloid. Polym. Sci., 270, 840 (1992).

19. Tong Y. Ko and E. M. Woo, "Sequential Crystallization and Annealing Induced Lamellar Polymorphism in Poly(ether ether ketone)", submitted to Polymer (1995).

20. J. Kim, M. E. Nichols, and R. E. Robertson, J. Polym. Sci., Phys. Ed., 32, 887 (1994).

21. M. Todoki and T. Kawaguchi, J. Polym. Sci., Phys.
Ed., 15, 1067 (1977).

22. D. C. Bassett, R. H. Olley, and I. A. Al-Raheil, Polymer, 29, 1745 (1988).

23. S. Z. D. Cheng, R. Pan, and B. Wunderlich, Makromol. Chem., 189, 2443 (1988).

24. J. I. Lauritzen and J. D. Hoffman, J. Res. Nat. Bur. Stand., U.S.A. A, 64, 73 (1960).

25. D. C. Bassett and D. Patel, Polymer, 35, 1855 (1994).

26. E. M. Woo and J. M. Chen, J. Appl. Polym. Sci., accepted (1994). 